\title{
Simultaneous Measurement of Air-water Interface Slope and the Point Spread Function for the Propagation of Laser Light
}

\author{
Jules S. Jaffe \\ Scripps Institution of Oceanography \\ 9500 Gilman Ave \\ La Jolla, CA 92093-0238 \\ phne : (858) 534-6101 fax : (858) 534-7641 email :jules@mpl.ucsd.edu \\ Award Number: N00014-06-1-0374 \\ http://jaffeweb.ucsd.edu
}

\section{LONG-TERM GOALS}

The long-term goal of this project is to measure, understand and be able to predict the propagation of light through the air-sea interface under various sea states.

\section{OBJECTIVES}

(1) Characterization of the point spread function of underwater light that has gone through the air water interface with exact coincident measurement of the surface wave field.

(2) Analysis of this data to formulate either empirical or theoretical relationships between the sea surface and the observed light spreading.

(3) Incorporation of the above results into an analysis and understanding of how difficult it will be to obtain detailed images through the air-sea interface as a function of sea state.

\section{APPROACH}

The experimental approach is to use the same light beam to both estimate the sea surface state and also to measure the spreading of the light below. The system accomplished this by using a laser, pointed at the sea surface, that is photographed from both above and below with digital cameras. A set of screens, upper and lower, were used to image the light reflected from the sea surface and hence, the angle and sea surface roughness, and the light that has passed through the air-sea interface.

Cameras, laser and reflective screens were mounted on a large frame, of approximate dimensions $5^{\prime} \mathrm{x}$ 5' x 20', constructed of 1-1/2 inch schedule 40 aluminum pipe connected together with Speed-Rail fittings. The upper camera used was a Cooke (Romulus, MI) Sensicam qe with a Tamron $6.5 \mathrm{~mm}$ lens (at f1.8) pointed directly down inside a security camera housing equipped with a green filter.

The laser used was a green laser, $(532 \mathrm{~nm}, 30 \mathrm{~mW})$, that was mounted to the top of the security camera housing with two lens holder clamps. The laser beam was aimed through a screen ( $1 / 2$ " acrylic sheet, $129 \times 162 \mathrm{~cm}$, sanded on one side with \#80 wet/dry sandpaper with a 1' hole), and was used to image the reflection of light from the sea surface. 


\section{Report Documentation Page}

Form Approved

OMB No. 0704-0188

Public reporting burden for the collection of information is estimated to average 1 hour per response, including the time for reviewing instructions, searching existing data sources, gathering and maintaining the data needed, and completing and reviewing the collection of information. Send comments regarding this burden estimate or any other aspect of this collection of information,

including suggestions for reducing this burden, to Washington Headquarters Services, Directorate for Information Operations and Reports, 1215 Jefferson Davis Highway, Suite 1204, Arlington

VA 22202-4302. Respondents should be aware that notwithstanding any other provision of law, no person shall be subject to a penalty for failing to comply with a collection of information if it

does not display a currently valid OMB control number.

1. REPORT DATE

30 SEP 2006

4. TITLE AND SUBTITLE

Simultaneous Measurement of Air-water Interface Slope and the Point Spread Function for the Propagation of Laser Light

6. AUTHOR(S)

7. PERFORMING ORGANIZATION NAME(S) AND ADDRESS(ES)

University of California, San Diego,Scripps Institution of Oceanography,9500 Gilman Drive,La Jolla,CA,92093

9. SPONSORING/MONITORING AGENCY NAME(S) AND ADDRESS(ES)

3. DATES COVERED

00-00-2006 to 00-00-2006

5a. CONTRACT NUMBER

5b. GRANT NUMBER

5c. PROGRAM ELEMENT NUMBER

5d. PROJECT NUMBER

5e. TASK NUMBER

5f. WORK UNIT NUMBER

8. PERFORMING ORGANIZATION REPORT NUMBER

10. SPONSOR/MONITOR'S ACRONYM(S)

11. SPONSOR/MONITOR'S REPORT NUMBER(S)

12. DISTRIBUTION/AVAILABILITY STATEMENT

Approved for public release; distribution unlimited

13. SUPPLEMENTARY NOTES

14. ABSTRACT

15. SUBJECT TERMS

16. SECURITY CLASSIFICATION OF:

a. REPORT

unclassified b. ABSTRACT

unclassified c. THIS PAGE

unclassified
17. LIMITATION OF ABSTRACT

Same as

Report (SAR)
18. NUMBER 19a. NAME OF

OF PAGES RESPONSIBLE PERSON

4 
The lower screen and camera, entirely underwater, consists of 40" wide Nytex nylon mesh stretched between two horizontal frame pipes. The lower camera is also a Cooke Sensicam qe housed in a pressure housing and mounted facing directly upward. Camera lens is a Tamron $6.5 \mathrm{~mm}$ set to f1.8 equipped with a green filter.

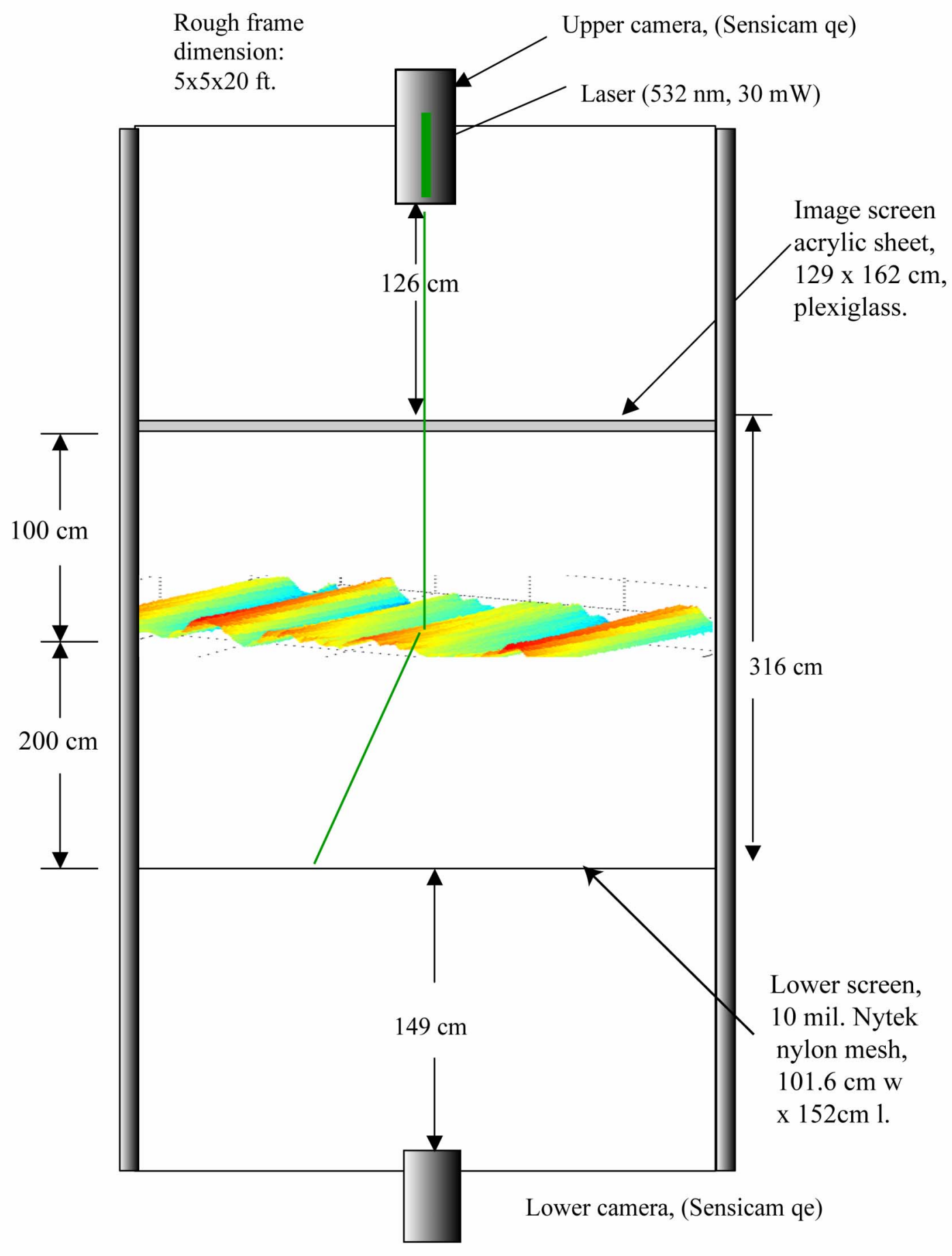

Figure 1: The Sea-surface and Sub-sea-surface measurement apparatus consisting of cameras, laser, viewing screens and frame. 

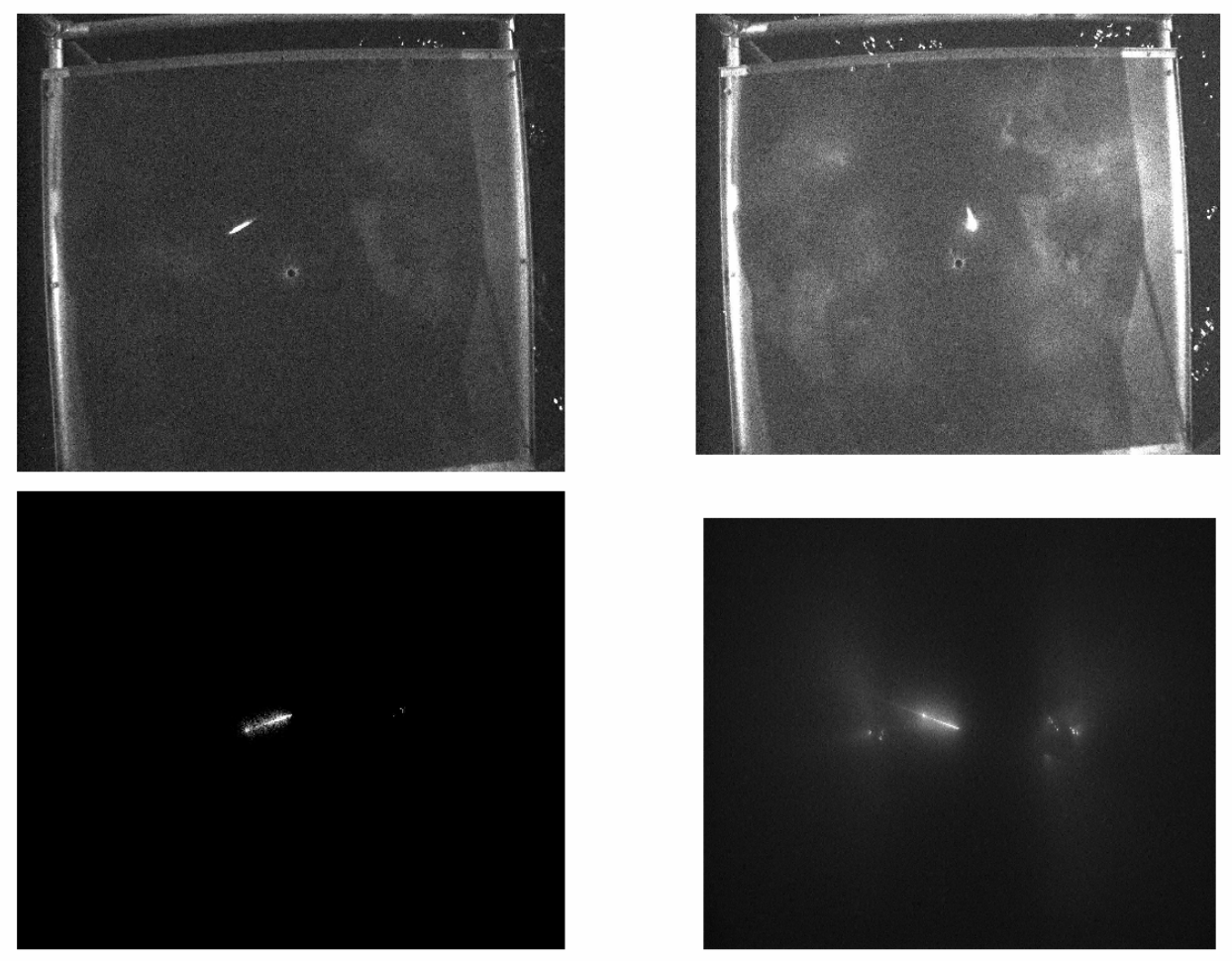

Figure 2: Images taken with the system. The upper image shows the light that has been reflected from the sea surface onto the upper screen. The lower image shows the light incident on the lower screen. The image patterns reveal interesting information about the temporal evolution of the sea state and the effects of that on the sub-sea surface light patterns.

\section{WORK COMPLETED}

The camera was deployed for several evening during the week of July $12^{\text {th }}$ at approximately 2000-PST. The upper camera shutter speed was set to $1 \mathrm{~ms}$, while the lower camera was set to $250 \mathrm{~ms}$. The wind at the time was approx. 5 knots and swells were 0.5 meters. Figure 2 shows a set of two images recorded with the device.

Data from the instrument are analyzed using Matlab. The images are first processed to correct the distortion caused by the wide angle lenses (barrel distortion) and also for the distortion caused by the flat port on the underwater camera housing. Once the images are corrected, the positions of the reflected and refracted beams are determined manually for each image pair. The sea surface tilt and height can be determined by solving an equation that uses the positions of the reflected and refracted laser beams, the index of refraction of seawater, and the distance between the upper and lower screens.

\section{RESULTS}

Results, so far, indicate that the under sea scattered light patterns are quite simple in mild sea state and wind $(<5 \mathrm{mph})$ however, the increase in sea state leads to various types of patterns that are currently under analysis. 


\section{IMPACT/APPLICATIONS}

The research described here is aimed at measuring a basic quantity that governs the propagation of light through the air-sea interface; the point spread function. Indeed, as revealed by our experiments, this function can be quite complex in even moderate sea states. This has important implications for future Navy systems that propose to use the propagation of light through the air sea interface for applications such as imaging.

\section{RELATED PROJECTS}

Dr. Jaffe currently is collaborating with a Seattle company, Aculight, on an SBIR II program to develop a next generation underwater lidar system. The system can also be used to image through the air sea interface and the results of this program will be interesting to consider in the context of that program. 